\title{
Diurnal Vitiations in Tension, Osmolarity, and the Composition of Nitrogen and Carbon Assimilates in Xylem Fluid of Prunus persica, Vitis Hybrid, and Pyrus communis
}

\author{
Peter C. Andersen, Brent V. Brodbeck, and Russell F. Mizell, III \\ North Florida Research and Education Center, University of Florida, Route 4, Box 4092, Monticello, \\ FL 32344
}

Additional index words. amino acids, grape, peach, pear, organic acids, sugars, xylem tension

\begin{abstract}
Diurnal variations in the chemical composition of xylem fluid have been established for many plant species exhibiting positive root pressure; similar patterns have not been well documented in transpiring plants. Diurnal changes in plant water status and xylem fluid chemistry were investigated for 'Flordaking' peach [Prunus persica (L.) Batsch ], 'Suwannee' grape (Vitis hybrid ), and 'Flordahome' pear (Pyrus communis L.). Xylem tension was maximum at 1200 or $1600 \mathrm{HR}$ and declined to $<0.5 \mathrm{MPa}$ before dawn. Xylem fluid osmolarity ranged from 10 to $27 \mathrm{~mm}$ and was not correlated with diurnal patterns of xylem tension. The combined concentration of amino acids and organic acids accounted for up to $70 \%, 45 \%, 55 \%$, and $23 \%$ of total osmolarity for irrigated $P$. persica, nonirrigated $P$. persica, Vitis, and $P$. communis, respectively. The concentration of total organic compounds in xylem fluid was numerically greatest at 0800 or $0900 \mathrm{HR}$. For irrigated $P$. persica the osmolarity of xylem fluid was reduced by $45 \%$ from 0800 to $1200 \mathrm{HR}, 1 \mathrm{~h}$ after irrigation, compared to only a $12 \%$ reduction from 0800 to $1200 \mathrm{HR}$ for nonirrigated trees. Asparagine, aspartic acid, glutamine, and glutamic acid were mainly responsible for diurnal changes in the concentration of total amino acids and organic $\mathbf{N}$ for $P$. persica; the diurnal variation in organic $\mathbf{N}$ for Vitis was due to glutamine. Arginine, rather than the amides, was the primary source of organic $\mathrm{N}$ in xylem fluid of $P$. communis, and there was no consistent diurnal change in the concentration of amino acids or organic $\mathrm{N}$. The predominant organic acids in all species examined were citric and malic acids. No consistent diurnal trend occurred in the concentration of organic acids or sugars in xylem fluid.
\end{abstract}

Plants with positive root pressure manifest diurnal changes in the concentrations of inorganic ions (Andersen and Brodbeck, 1989a; Masuda, 1989; Wallace et al., 1966) and primary organic compounds (Andersen and Brodbeck, 1989a; Stoev et al., 1959; van Die, 1959) in xylem fluid. Positive root pressure is responsible for a small proportion of the volume flux in xylem vessels of terrestrial plants (Scholander et al., 1965); for many woody species, positive root pressure only occurs just before budbreak.

Most terrestrial plant species manifest large diurnal variations in plant water status. For transpiring plants, xylem tensions are typically maximum during midday and minimum at night. Despite much information concerning diurnal changes in plant water relations, there have been surprisingly few studies that have addressed concomitant changes in xylem fluid chemistry. Characterization of diurnal rhythms in the chemical profile of xylem fluid are relevant to studies concerning nutrient partitioning and sourcesink relationships. The only woody species for which a diurnal cycle in the concentration of primary organic compounds in xylem fluid has been documented under typical day-night variations in plant water status has been Lagerstroemia indica (Andersen et al., 1993). A distinct circadian rhythm in the concentration of amino acids with a maximum during the daylight hours was endogenous, not mediated by changes in plant water status, persisted in constant darkness and was terminated under conditions of continuous light (Andersen et al., 1993). Changes in concentrations of glutamine were mainly responsible for the diurnal changes in xylem fluid chemistry in $L$. indica.

Received for publication 11 Oct. 1994. Accepted for publication 5 Jan. 1995. Univ. of Florida Agricultural Experiment Station Journal Series no. R-03772. Use of trade names does not imply endorsement of products named nor criticism of similar products not mentioned. The authors wish to acknowledge the helpful reviews of B. Schaffer and K. Koch. The cost of publishing this paper was defrayed in part by the payment of page charges. Under postal regulations, this paper therefore must be hereby marked advertisement solely to indicate this fact.
In this study, we measured the diurnal changes in xylem tension, xylem fluid osmolarity, and the concentrations of amino acids, organic acids, and sugars in xylem fluid of Prunus persica, Vitis hybrid, and Pyrus communis to examine the extent to which xylem fluid chemistry varies diurnally in plants that exhibit transpiration. These species, representing different families, were selected to ensure a wide range in xylem chemistry. The amide glutamine is the major amino acid in xylem fluid of Vitis spp. (Andersen et al., 1989a-c) as in L. indica (Andersen et al., 1993), whereas, in $P$. persica, concentrations of asparagine and glutamine predominate (Brodbeck et al., 1990). Arginine is the major amino acid in the xylem fluid of P. communis (P.C. Andersen, unpublished data). In addition, we investigated whether plant water status, as influenced by daily irrigation, has an influence on the diurnal pattern of xylem fluid chemistry in P. persica.

\section{Materials and Methods}

Plant material. Experiments were conducted at the Univ. of Florida, North Florida Agricultural Research Center, Monticello, Fla. Separate blocks of irrigated and nonirrigated 'Flordaking' peach, irrigated 'Suwannee' grape, and nonirrigated 'Flordahome' pear were examined. Each block consisted of 30 to 200 plants of bearing age that had fruited earlier in the spring or summer. Soil type was a Dothan loamy sand (Plinthic paleudults) containing about $1 \%$ organic matter. Standard cultural practices were used and 2-m in-row weed-free strips were maintained with herbicides. Plants in irrigated plots received drip irrigation (about 8 liters) daily, from 1100 to 1200 HR. Plants were fertilized during February and June with $337 \mathrm{~kg} \cdot \mathrm{ha}^{-1} 10 \mathrm{~N} 4.3 \mathrm{P}-8.3 \mathrm{~K}$ with micronutrients. Total $\mathrm{N}$ was in the form of $\mathrm{NH}_{4}^{+}(85 \%)$ and $\mathrm{NO}_{3}^{-}(15 \%)$.

Extraction of xylem fluid. One or two terminal shoots about 25 to $35 \mathrm{~cm}$ long were excised from each plant and placed in a pressure chamber apparatus (Scholander et al., 1965). Tissue exterior to the 
xylem was removed from the 2 to $4 \mathrm{~cm}$ stem section protruding from the chamber to minimize contamination of xylem fluid by extraxylellary tissue. After recording xylem tension (i.e., the pressure at which fluid was observed at the cut surface of the stem), the pressure was increased $0.5 \mathrm{MPa}$ more than the balance pressure for $90 \mathrm{sec}$ (Andersen et al., 1993, 1995; Berger et al., 1994). The first two drops of fluid were discarded to minimize contamination from cut cells. Xylem fluid was collected in 1.5-ml Eppendorf tubes, then sealed and frozen at $-20 \mathrm{C}$. Xylem fluid was collected at $0800,1200,1600,2000$, and 2400 HR on 13 July 1988 for $P$. persica and at 600, 0900, 1200, 1600, and 2100 HR on 14 July 1988 for Vitis hybrid and $P$. communis.

Chemical analyses. Xylem fluid was thawed to room temperature, and total osmolarity was determined with a vapor pressure osmometer (model 5500; Wescor, Logan, Utah). An osmometer technically measures osmolality $\left(\mathrm{mmol} \cdot \mathrm{kg}^{-1}\right)$; however, since osmolality and osmolarity are virtually identical for dilute solutions, we will use osmolarity to facilitate comparisons to the concentrations of organic compounds.

Samples were centrifuged at $1200 \times \mathrm{g}$ through 10,000 MW filters (Millipore Corp., Bedford, Mass.). Supernatant was divided into subsamples for hydrolysis and analysis of amino acids and for analysis of organic acids and sugars (Andersen et al., 1993). Small sample volumes (400 to $1000 \mu \mathrm{l})$ precluded accurate quantification of inorganic ions.

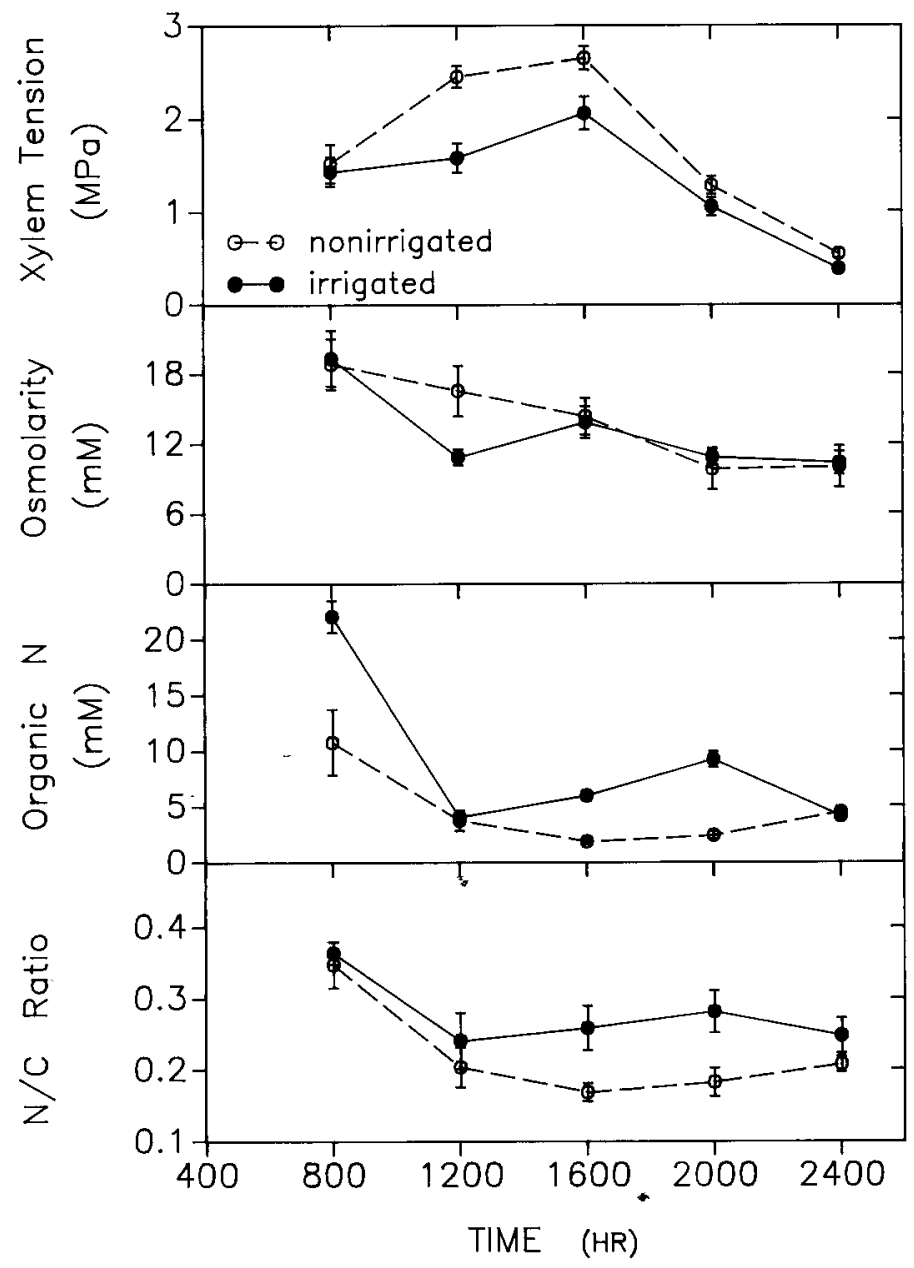

Fig. 1. Diurnal variations in xylem fluid tension, the osmolarity of xylem fluid, the concentrations of total organic $\mathrm{N}$, and the ratio of organic $\mathrm{N}$ to organic $\mathrm{C}$ in xylem fluid of irrigated and nonirrigated Prunus persica 'Flordaking'. Values are means $\pm \mathrm{SE}, \mathrm{n}=4$.
The analyses of amino acids, organic acids, and sugars have been described in detail (Andersen et al., 1993). In brief, amino acids were derivatized with phenylisothiocyanate and quantified on a high-performance liquid chromatography (HPLC) gradient system with a ultraviolet (UV) detector and a Pico Tag column (Waters Division, Millipore Corp., Milliford, Mass.). Organic acid analyses were performed on a Waters HPLC system equipped with a variable-wavelength UV detector (model 166; Beckman Corp., San Roman, Calif.) and an polymeric cation exchange column (Ion-300; Interaction Corp., San Jose, Calif.). Sugars were quantified on a Waters HPLC system with a pulse amperometric detector equipped with a gold electrode and an Ion-Pat ion exchange column (Dionex Corp., Sunnyvale, Calif.).

Subsets of nonhydrolyzed samples were used 1) for the quantification of amides to their respective acids since hydrolysis resulted in delamination and 2) to facilitate peak separation of succinic acid and an unknown compound with the use of a diode array detector (model 168; Beckman) equipped with an Ion-300 polymeric cation exchange column.

Organic $\mathrm{N}$ and $\mathrm{C}$ were calculated from the concentration of each amino acid, organic acid, and sugar quantified. The concentration of total organic compounds is defined as the combined concentration of amino acids, organic acids, and sugars.

Statistics. Xylem fluid was collected from four plants of each species or treatment at the times specified above. Means and standard errors of the means were computed for xylem tension, xylem fluid osmolarity, and the concentration of total and individual amino acids, organic acids, sugars, total organic compounds, organic $\mathrm{N}$, and the ratio of organic $\mathrm{N}$ to organic $\mathrm{C}$. Although data for the individual amino acids, organic acids, and sugars were collected and analyzed for all the time periods described above, data are presented only for 0800 and $2400 \mathrm{HR}$ for $P$. persica and 0900 and $2100 \mathrm{HR}$ for Vitis and P. communis, the time periods for which greatest differences were observed.

\section{Results}

Xylem tension was maximum during midday (1200 or $1600 \mathrm{HR}$ ) and or $1600 \mathrm{HR}$ ) and minimum before dawn (Fig. 1, Table 1). Maximum xylem tensions of 2.1, 2.7, 1.5, and 1.2 MPa were recorded for irrigated $P$. persica, nonirrigated $P$. persica, irrigated Vitis, and nonirrigated $P$. communis trees. Predawn xylem tension ranged from 0.2 to $0.5 \mathrm{MPa}$.

Xylem fluid osmolarity varied from 10 to $27 \mathrm{~mm}$ among species and times of day (Fig. 1, Table 1 ). Although xylem fluid osmolarity was maximum during the morning, no consistent correlation existed between xylem tension and osmolarity. The osmolarity of xylem fluid was maximum (19 mM) for P. persica at $0800 \mathrm{HR}$ and declined to $10 \mathrm{~mm}$ at night. Xylem fluid osmolarity was maximum at 0900 or $1200 \mathrm{HR}$ for Vitis and P. communis and declined toward predawn with two exceptions (i.e., $1600 \mathrm{HR}$ for Vitis and $2100 \mathrm{HR}$ for $P$. communis). The combined sum concentration of amino acids and organic acids accounted for up to $70 \%, 45 \%, 55 \%$, and $23 \%$ of total osmolarity of xylem fluid from irrigated $P$. persica, nonirrigated $P$. persica, Vitis, and P. communis, respectively (Fig. 2, Table 1).

The concentration of total amino acids and organic $\mathrm{N}$ in xylem fluid was numerically highest at 0800 or $0900 \mathrm{HR}$ for all species (Figs. 1 and 2, Table 1), although diurnal differences were minimal for $P$. communis. The concentrations of amino acids were particularly high ( $11.4 \mathrm{~mm}$ ) for irrigated $P$. persica at $0800 \mathrm{HR}$. A fairly consistent decrease in the concentration of amino acids occurred from 0800 or 0900 HR until 2000 or 2100 HR occured for nonirrigated $P$. persica and Vitis hybrid. 
Table 1. Diurnal variations in xylem fluid tension, the osmolatity of xylem fluid, and concentrations of total amino acids, organic acids, sugars, total Organic compounds quantified, total organic N and the ratio of organic N to organic C (N : C) in xylem fluid of Vitis hybrid 'Suwannee' and Pyrus communis 'Flordahome'.

\begin{tabular}{|c|c|c|c|c|c|}
\hline \multirow{2}{*}{$\begin{array}{l}\text { Species or } \\
\text { variable }\end{array}$} & \multicolumn{5}{|c|}{ Time (HR) } \\
\hline & 0600 & 0900 & 1200 & 1600 & 2100 \\
\hline \multicolumn{6}{|l|}{ Vitis hybrid } \\
\hline Xylem tension $(\mathrm{MPa})$ & $0.61 \pm 0.04^{z}$ & $0.93 \pm 0.09$ & $1.48 \pm 0.15$ & $1.50 \pm 0.08$ & $0.44 \pm 0.03$ \\
\hline Osmolarity (mM) & $17.0 \pm 0.4$ & $21.8 \pm 4.7$ & $23.5 \pm 0.80$ & $16.0 \pm 0.50$ & $18.8 \pm 0.90$ \\
\hline Amino acids (mM) & $2.50 \pm 0.35$ & $2.98 \pm 0.48$ & $2.49 \pm 0.29$ & $2.61 \pm 0.50$ & $1.12 \pm 0.07$ \\
\hline Organic acids (mM) & $3.47 \pm 0.62$ & $5.93 \pm 0.67$ & $4.87 \pm 0.27$ & $6.08 \pm 1.54$ & $5.43 \pm 0.38$ \\
\hline Sugars.(mM) & $0.17 \pm 0.05$ & $0.54 \pm 0.15$ & $0.55 \pm 0.16$ & $0.20 \pm 0.06$ & $0.39 \pm 0.12$ \\
\hline Total organics (mM) & $6.15 \pm 0.44$ & $9.56 \pm 0.96$ & $7.91 \pm 0.47$ & $8.89 \pm 2.10$ & $6.94 \pm 0.49$ \\
\hline Organic $\mathrm{N}(\mathrm{mM})$ & $4.64 \pm 0.73$ & $5.62 \pm 0.89$ & $4.67 \pm 0.59$ & $4.84 \pm 0.98$ & $2.06 \pm 0.15$ \\
\hline $\mathrm{N}: \mathrm{C}$ & $0.17 \pm 0.03$ & $0.13 \pm 0.02$ & $0.13 \pm 0.01$ & $0.13 \pm 0.01$ & $0.07 \pm 0.01$ \\
\hline \multicolumn{6}{|l|}{ Pyrus communis } \\
\hline Xylem tension (MPa) & $0.21 \pm 0.04$ & $0.73 \pm 0.09$ & $1.18 \pm 0.07$ & $0.70 \pm 0.12$ & $0.61 \pm 0.10$ \\
\hline Osmolarity (mM) & $12.3 \pm 1.0$ & $27.3 \pm 3.2$ & $20.3 \pm 1.8$ & $20.8 \pm 3.4$ & $26.5 \pm 3.0$ \\
\hline Amino acids (mM) & $1.22 \pm 0.11$ & $1.92 \pm 0.26$ & $1.88 \pm 0.36$ & $1.74 \pm 0.29$ & $1.86 \pm 0.35$ \\
\hline Organic acids (mM) & $1.62 \pm 0.28$ & $2.76 \pm 0.23$ & $1.60 \pm 0.19$ & $2.25 \pm 0.58$ & $1.71 \pm 0.01$ \\
\hline Sugars $(\mathrm{mM})$ & $0.18 \pm 0.04$ & $0.37 \pm 0.09$ & $0.21 \pm 0.06$ & $0.37 \pm 0.03$ & $0.27 \pm 0.09^{i}$ \\
\hline Total organics (mM) & $2.97 \pm 0.37$ & $4.99 \pm 0.23$ & $3.65 \pm 0.53$ & $4.29 \pm 0.83$ & $3.78 \pm 0.27$ \\
\hline Organic $\mathbf{N}(\mathrm{mM})$ & $2.74 \pm 0.16$ & $3.91 \pm 0.71$ & $3.61 \pm 0.71$ & $3.31 \pm 0.57$ & $3.75 \pm 0.90$ \\
\hline $\mathrm{N}: \mathrm{C}$ & $0.19 . \pm 0.07$ & $0.17 \pm 0.02$ & $0.21 \pm 0.02$ & $0.16 \pm 0.02$ & $0.21 \pm 0.04$ \\
\hline
\end{tabular}

${ }^{\overline{\mathrm{z}} \text { Values are means } \pm \text { SE, } \mathrm{n}=4 \text {. }}$

The concentration of total amino acids was much greater than total organic acids in P. persica (Fig. 2), yet concentrations of organic acids were generally greater than or equal to that of amino acids in Vitis and P. communis (Table 1). All species examined lacked a consistent diurnal change in the concentration of organic acids in xylem fluid. The concentration of sugars was very low, and typically contributed to only $1 \%$ to $2 \%$ of total osmolarity (Table 1 ). The trend in the concentration of total organic compounds for $P$. persica and Vitis resembled changes in amino acid concentration, with a maximum observed at 0800 or $0900 \mathrm{HR}$, respectively. For $P$. communis, the concentration of organic acids contributed heavily to the trend in total organic compounds. The ratio of organic $\mathrm{N}$ to organic $\mathrm{C}$ in organic compounds varied from about 0.07 in P. communis at $2100 \mathrm{HR}$ to 0.36 in P. persica at $0800 \mathrm{HR}$.

The predominant organic compounds in xylem fluid were asparagine, aspartic acid, glutamine, glutamic acid, arginine $(P$. communis only), citric acid, and malic acid (Tables 2 and 3 ). Although the high concentration of total amino acids recorded at $0800 \mathrm{HR}$ in xylem fluid of irrigated $P$. persica was mainly a function of the amides and their respective acids, many amino acids varied asynchronously in concentration through the day (Table 2; data not shown pertaining to time periods other than for 0800 and $2400 \mathrm{HR}$ ). For example, the amides plus their respective acids represented $90 \%$ and $55 \%$ of the amino acid profile at $0800 \mathrm{HR}$ and $70 \%$ to $75 \%$ of the amino acid profile at $2400 \mathrm{HR}$ for irrigated and nonirrigated $P$. persica, respectively. Only alanine, leucine (which belongs to the alanine family of amino acids), and methionine (a sulfur amino acid) were higher in concentration at $2400 \mathrm{HR}$ compared to $0800 \mathrm{HR}$.

Malic acid was the predominant organic acid at all time periods and accounted for over $50 \%$ of the total organic acids quantified. The diurnal changes in the concentration of most organic acids were usually opposite for irrigated (higher at $0800 \mathrm{HR}$ ) and nonirrigated (higher at $2400 \mathrm{HR}$ ) P. persica.

The concentration of glutamine in Vitis xylem fluid represented up to $90 \%$ of total amino acids (Table 3 ). Glutamine was responsible for most of the diurnal cycling of total amino acids, although

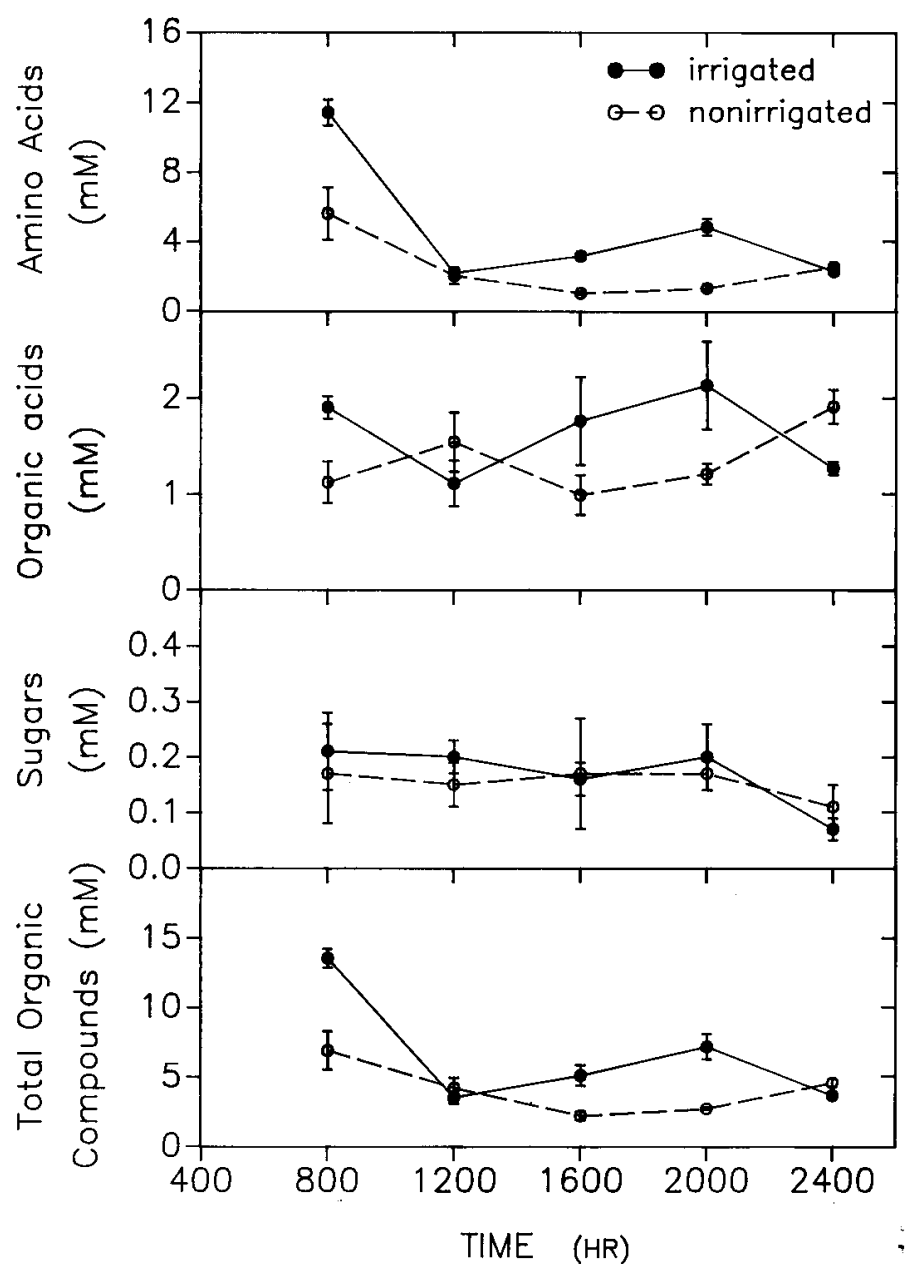

Fig. 2. Diurnal variations in the concentrations of total amino acids, organic acids, sugars, and organic compounds quantified in xylem fluid of irrigated and nonirrigated Prunus persica 'Flordaking', Values are means $+\mathrm{SE}, \mathrm{n}=4$. 
fluid not accounted for by primary organic compounds was likely in the form of inorganic ions.

The pronounced peak in the concentration of glutamine-glutamic acid or asparagine-aspartic acid for irrigated and nonirrigated $P$. persica was responsible for the maximum concentration of total amino acids, organic $\mathrm{N}$, total organic compounds, and the $\mathrm{N}: \mathrm{C}$ ratio at $0800 \mathrm{HR}$ (Figs. 1 and 2, Table 2). The concentration of glutamine also varied diurnally in xylem fluid of Vitis, whereas in $P$. communis, in which amides did not predominate, a diurnal trend in amino acids did not occur (Tables 1 and 3). The high $\mathrm{N}$ to $\mathrm{C}$ ratio represented in primary compounds of xylem fluid from irrigated $P$. persica at $0800 \mathrm{HR}$ was significantly higher than that of pure protein (Gnaiger and Bitterlich 1984) due to the high concentration of the amides. The amides are the predominant nitrogenous compound in xylem fluid of many woody species (Andersen and Brodbeck, 1989a, 1989b, 1991; Andersen et al., 1989, 1993; Clark et al., 1986; Glad et al., 1992) and are readily converted to many other amino acids (Lacey and Wilmore, 1990; Pate, 1980). Andersen et al. (1993) also documented that glutamine mainly accounted for the circadian rhythm in the concentration of amino acids (and organic $\mathrm{N}$ ) in xylem fluid of L. indica. This rhythm persisted and was accentuated after 3 days of constant darkness.

The mechanisms responsible for the diurnal pattern of organic
$\mathrm{N}$ concentrations in xylem fluid are not known. However, the diurnal trend was not mediated by plant water status since changes in chemistry were not correlated with xylem tension in any of the plant species thus far tested. Also, this trend occurred for irrigated and nonirrigated P. persica (Fig. 1, Table 2). A marked (i.e., 45\%) decline in osmolarity and total amino acids in xylem fluid of $P$. persica occurred at $1200 \mathrm{HR}, 1 \mathrm{~h}$ after irrigation, whereas a more gradual reduction occurred for nonirrigated $P$. persica. Although the significance of irrigation (and irrigation timing) on $\mathrm{N}$ flux in xylem vessels and $\mathrm{N}$ partitioning distribution in plant tissues have not yet been adequately explored, these data indicate that an irrigation episode may drastically reduce osmolarity and the concentration of organic $\mathrm{N}$ in xylem fluid.

Changes in organic $\mathrm{N}$ may be due to differences in the rate of uptake and assimilation of $\mathrm{N}$ by roots. Nitrogen derived from soil $\mathrm{NO}_{3}^{-}$or $\mathrm{NH}_{4}^{+}$is initially incorporated into the amide- $\mathrm{N}$ of glutamine and later appears in other amino acids (Kate, 1980; Pate, 1980). The circadian rhythm in organic $\mathrm{N}$ may be due to the recycling of $\mathrm{N}$ between xylem and phloem or to the differential transfer into or out of xylem vessels (Clausen and Apel, 1991; Cooper and Clarkson, 1989; Simpson et al., 1982; van Bel, 1990). However, the 1 - to 1.5 -h interval between dawn and the 0800 HR collection period is not consistent with current day's photoassimilate being

Table 3. Diurnal variations in the concentration of amino acids, organic acids, and sugars in the xylem fluid of Vitis hybrid 'Suwannee' and Pyrus communis 'Florahome'.

\begin{tabular}{|c|c|c|c|c|c|}
\hline \multirow[b]{3}{*}{ Chemical compound } & & \multicolumn{4}{|c|}{ Loncn $(\mu \mathrm{M})$} \\
\hline & & \multicolumn{2}{|c|}{ Vitis } & \multicolumn{2}{|c|}{ P. communis } \\
\hline & & $0900 \mathrm{HR}$ & $2100 \mathrm{HR}$ & $0900 \mathrm{HR}$ & $2100 \mathrm{HR}$ \\
\hline \multicolumn{6}{|l|}{ Amino acid } \\
\hline $\mathrm{ASN}^{\mathrm{z}}$ & & $15 \pm 3^{y}$ & $8 \pm 1$ & $355 \pm 59$ & $387 \pm 116$ \\
\hline ASP & & $60 \pm 11$ & $30 \pm 5$ & $290 \pm 48$ & $167 \pm 50$ \\
\hline GLU & & $119 \pm 19$ & $37 \pm 3$ & $248 \pm 18$ & $308 \pm 63$ \\
\hline GLN & & $2267 \pm 366$ & $708 \pm 61$ & $70 \pm 5$ & $34 \pm 7$ \\
\hline SER & & $37 \pm 6$ & $15 \pm 6$ & $46 \pm 6$ & $52 \pm 9$ \\
\hline GLY & & $155 \pm 49$ & $98 \pm 22$ & $125 \pm 35$ & $109 \pm 29$ \\
\hline HIS & & $1 \pm 1$ & $0 \pm 0$ & $2 \pm 1$ & $3 \pm 0$ \\
\hline ARG & & $85 \pm 25$ & $74 \pm 7$ & $500 \pm 172$ & $485 \pm 199$ \\
\hline ALA & & $59 \pm 16$ & $28 \pm 5$ & $53 \pm 4$ & $78 \pm 24$ \\
\hline THR & & $25 \pm 5$ & $8 \pm 1$ & $56 \pm 10$ & $47 \pm 10$ \\
\hline PRO & & $39 \pm 5$ & $29 \pm 2$ & $36 \pm 3$ & $40 \pm 6$ \\
\hline TYR & & $8 \pm 3$ & $2 \pm 1$ & $16 \pm 7$ & $8 \pm 2$ \\
\hline VAL & & $26 \pm 9$ & $16 \pm 1$ & $34 \pm 3$ & $24 \pm 6$ \\
\hline CYS & & $16 \pm 7$ & $7 \pm 5$ & $2 \pm 1$ & $26 \pm 15$ \\
\hline MET & & $12 \pm 4$ & $6 \pm 3$ & $9 \pm 5$ & $6 \pm 3$ \\
\hline ILE & & $19 \pm 5$ & $18 \pm 2$ & $29 \pm 5$ & $31 \pm 4$ \\
\hline LEU & & $12 \pm 3$ & $11 \pm 1$ & $18 \pm 1$ & $16 \pm 3$ \\
\hline PHE & $s$ & $11 \pm 2$ & $12 \pm 3$ & $15 \pm 9$ & $12 \pm 5$ \\
\hline LYS & & $12 \pm 5$ & $9 \pm 0$ & $18 \pm 4$ & $21 \pm 6$ \\
\hline \multicolumn{6}{|l|}{ Organic acid } \\
\hline OX & & $19 \pm 5$ & $21 \pm 10$ & $111 \pm 24$ & $88 \pm 2$ \\
\hline CIT & & $326 \pm 63$ & $224 \pm 76$ & $230 \pm 90$ & $269 \pm 10$ \\
\hline MAL & & $718 \pm 146$ & $1104 \pm 172$ & $2189 \pm 282$ & $1170 \pm 27$ \\
\hline SUC & & $413 \pm 121$ & $389 \pm 61$ & $208 \pm 39$ & $149 \pm 5$ \\
\hline FUM & & $39 \pm 6$ & $32 \pm 7$ & $26 \pm 2$ & $32 \pm 4$ \\
\hline Sugar & & • & & & \\
\hline SUCR & & $158 \pm 58$ & $93 \pm 33$ & $128 \pm 39$ & $75 \pm 24$ \\
\hline FRUC & & $158 \pm 41$ & $154 \pm 55$ & $135 \pm 30$ & $119 \pm 43$ \\
\hline GLUC & & $228 \pm 66$ & $147 \pm 75$ & $103 \pm 25$ & $75 \pm 31$ \\
\hline
\end{tabular}

${ }^{2}$ Ratios of ASN : ASP and of GLN : GLU were determined for a pooled sample at each time period.

${ }^{y}$ Values are means \pm SE, $n=4$. 
the $\mathrm{C}$ source for the enriched N-status of xylem fluid. Alternatively; given that the synthesis and subsequent conversion of amino acids to glutamine occurs before loading in xylem vessels (Clausen and Apel, 1991; Sauter and van Cleve, 1992), the enriched N-status of xylem fluid at 0800 to 0900 HR may result from the export of amino acids from preexisting pools in xylem parenchyma cells.

A circadian rhythm in nitrate reductase (NR) activity with a maximum during daylight hours often occurs in leaves (DeDeng et al., 1989; Reed et al., 1983; Rufty et al., 1984) and roots (Queiroz et al., 1993). In leaves of Nicotiana tabacum, NR activity was correlated with the concentration of malate; however, the rhythm persisted in continuous light and was terminated in constant darkness (DeDeng et al., 1989). Malate concentrations in xylem fluid were not correlated with amides or organic $\mathrm{N}$ in L. indica (Andersen et al., 1993) or in the species used in the current study, and constant darkness terminated diurnal patterns for NR while continuous light terminated diurnal patterns in xylem composition (Andersen et al., 1993). Thus, we cannot attribute the diurnal pattern in xylem chemistry to changes in NR activity.

The enzymes responsible for the synthesis of glutamine from oxaloacetate and ammonia are glutamine synthetase (GS) and glutamate synthase (GOGAT). The activity of GS and GOGAT in Sinapis alba L. (Schmidt and Mohr, 1989) and Pinus sylvestris L. (Elmlinger and Mohr, 1991, 1992) was controlled by light and was mediated by phytochrome; nitrate concentrations had a minor role and $\mathrm{NH}_{4}^{+}$actually inhibited GS activity (Elmlinger and Mohr, 1991, 1992; Schmidt and Mohr, 1989). Whether the increased concentration of glutamine in xylem fluid during the morning is a result of phytochrome-mediated increases in glutamine synthesis by GS and/or GOGAT has not been determined. However, plant species thus far tested that have had amides as the primary nitrogenous compounds in xylem fluid [i.e., L. indica (Andersen et al., 1993); P. persica (Table 2); V. rotundifolia (Andersen and Brodbeck, 1989a); Vitis hybrid (Table 3)] have all manifested diurnal variations in the concentrations of amino acids and organic N. In contrast, $P$. communis did not exhibit this diurnal pattern nor did it have significant levels of either amide.

\section{Conclusions}

The diurnal fluctuation in plant water relations is characteristic of terrestrial plant species; however, diurnal variations in xylem fluid osmolarity and the concentration of organic $\mathrm{N}$ in xylem fluid (and likely the $\mathrm{N}$ flux to foliar tissue) also appears to be a widespread phenomenon. Diurnal changes in the concentration of amino acids and organic $\mathrm{N}$ occurred in the three species tested having the amides as the primary nitrogenous compound in xylem fluid (Tables. 2 and 3) (Andersen et al., 1993). The enriched $\mathrm{N}$ status of xylem fluid during the morning hours is concomitant with increases in photosynthesis and other physiological activities. The importance of the diurnal variations of organic $\mathrm{N}$ in xylem fluid to $\mathrm{N}$ loading and transport to aerial plant tissue and to plant $\mathrm{N}$ balance remains to be determined.

\section{Literature Cited}

Andersen, P.C. and B.V. Brodbeck. 1989a. Diurnal and temporal changes in the chemical profile of xylem exudate from Vitis rotundifolia. Physiol. Plant. 75:63-70.

Andersen, P.C. and B.V. Brodbeck. 1989b. Chemical composition of xylem exudate from bleeding spurs of Vitis rotundifolia Noble and Vitis hybrid Suwannee in relation to pruning date. Amer. J. Enol. Viticult. 40:155-160.
Andersen, P.C. and B.V. Brodbeck. 1989c. Temperature and temperature preconditioning on flux and chemical composition of xylem exudate from muscadine grapevines. J. Amer. Soc. Hort. Sci. 114:440-444.

Andersen, P.C. and B.V. Brodbeck. 1991. Influence of fertilization on xylem fluid chemistry of Vitis rotundifolia Noble and Vitis hybrid Suwannee. Amer. J. Enol. Viticult. 42:245-251.

Andersen, P. C., B.V. Brodbeck, and R.F. Mizell, III. 1989. Metabolism of amino acids, organic acids and sugars extracted from the xylem fluid of four host plants by adult Homalodisca coagulata. Entomol. Expt. Appl. 50:149-159.

Andersen, P. C., B.V. Brodbeck, and R.F. Mizell, III. 1993. Diurnal variations of amino acids and organic acids in xylem fluid from Lagerstroemia indica : an endogenous circadian rhythm. Physiol. Plant. 89:783-790.

Andersen, P. C., B.V. Brodbeck, and R.F. Mizell, III. 1995. Water-stress and nutrition-mediated changes in the water relations and the amino acids, organic acids and sugars in xylem fluid of Prunus salicina and Lagerstroemia indica. J. Amer. Soc. Hort. Sci. 120:36-42.

Berger, A., R. Oren, and E-D Schulze. 1994. Element concentrations in xylem sap of Picea abies (L.) Karst seedlings by various methods under different environmental conditions. Tree Physiol. 14:111-128.

Brodbeck, B. V., R.F. Mizell, III, W.J. French, P.C. Andersen, and J.H. Aldrich. 1990. Amino acids as determinants of host preference for the xylem feeding leafhopper, Homalodisca coagulata (Homoptera: Cicadellidae). Oecologia 83:338-345.

Clark, C.J., P.T. Holland, and G.S. 1986. Chemical composition of bleeding xylem sap from kiwifruit vines. Ann. Bet. 58:353-362.

Clausen, S. and K. Apel. 1991. Seasonal changes in the concentration of the major storage protein and its mRNA in xylem ray cells of poplar trees. Plant Mol. Biol. 17:669-678.

Cooper, H.D. and D.T. Clarkson. 1989. Cycling of amino-nitrogen and other nutrients between shoots and roots in cereals-A possible mechanism integrating shoot and root in the regulation of nutrient uptake. J. Expt. Bet. 40:753-762.

DeDeng, M., T. Moureaux, and T. Lamaze. 1989. Diurnal and circadian fluctuation of malate levels and its close relationship to nitrate reductase activity in tobacco leaves. Plant Sci. 65:191-197.

Elmlinger, M.W. and H. Mohr. 1991. Coaction of blue/ultraviolet-A light and light absorbed by phytochrome in controlling the appearance of ferredoxin-dependent glutamate synthase in the Scots pine (Pinus sylvestris L.) seedling. Planta 183:374-380.

Elmlinger, M.W. and H. Mohr. 1992. Glutamine synthetase in Scots pine seedlings and its control by blue light absorbed by phytochrome. Planta 188:396-402.

Ferguson, A. R., J.A. Eiseman, and J.A. Leonard. 1983. Xylem sap from Actinidia chinensis: Seasonal changes in composition. Ann. Bet. 51:823833.

Glad, C., J.L. Regnard, Y. Querou, O. Brun, and J.F. Morot-Gaudry. 1992. Flux and chemical composition of xylem exudates from chardonnay grapevines: temporal evolution and effect ofrecut. Amer. J. Enol. Viticult. 43:275-282.

Gnaiger, E. and G. Bitterlich. 1984. Proximate biochemical composition and caloric content calculated from elemental CHN analysis: a stoichiometric concept. Oecologia 62:289-298.

Kate, T. 1980. Nitrogen assimilation by a citrus tree. 2. Assimilation of labelled ammonium and nitrate by detached leaves in light and dark. Physiol. Plant. 50:304-308.

Kliewer, W.M. 1967. Annual cyclic changes in the concentration of free amino acids in grapevine. Amer. J. Enol. Viticult. 18:126-136.

Lacey, J. M. and D.W. Wilmore. 1990. Is glutamine a conditionally essential amino acid? Nutr. Rev. 48:297-309.

Marangoni, B., C. Vitagliano, and E. Peterlunger. 1986. The effect of defoliation on the composition of xylem sap from Cabernet franc grapevines. Amer. J. Enol. Viticult. 37:259-262.

Masuda, M. 1989. Mineral concentrations in xylem exudate of tomato and cucumber plants at midday and midnight. J. Jpn. Hort. Sci. 58:619-625.

Queiroz, C. G. S., A. B. Rena, A. T. Cordeiro, and J. D. Alves. 1993. Diurnal rhythm in nitrate reductase activity of Coffea arabica L. shoots and roots. Pesq. agropec. bras. Brasilia 28:787-795. 
Pate, J.S. 1980. Transport and partitioning of nitrogenous solutes. Annu. Rev. Plant Physiol. 31:313-340.

Reed, A.J., D.T. Canvin, J.H. Sherrard, and R.H. Hageman. 1983. Assimilation of $\left[{ }^{15} \mathrm{~N}\right]$ nitrate and $\left[{ }^{15} \mathrm{~N}\right]$ nitrite in leaves of five plant species under light and dark conditions. Plant Physiol. 71:291-294.

Roubelakis-Angelakis, K.A. and W.M. Kliewer. 1979. The composition of bleeding sap from Thompson Seedless grapevines as affected by nitrogen fertilization. Amer. J. Enol. Viticult. 30:14-18.

Rufty Jr., T. W., D.W. Israel, and R.J. Volk. 1984. Assimilation of ${ }^{15} \mathrm{NO}_{3}$ taken up by plants in the light and in the dark. Plant Physiol. 76:769-775.

Sauter, J.J. and B. van Cleve. 1992. Seasonal variation of amino acids in the xylem sap of "Populus x canadensis" and its relation to protein body mobilization. Trees 7:26-32.

Schmidt, S. and H. Mohr. 1989. Regulation of the appearance of glutamine synthetase in mustard (Sinapis alba L.) cotyledons by light, nitrate and ammonium. Planta 177:526-534.

Scholauder, P.F., H.T. Hammel, E.D. Bradstreet, and E.A. Hemmingsen. 1965. Sap pressure in vascular plants. Science 148:339-346.

Simpson, R.J., H. Lambers, and M.J. Dalling. 1982. Translocation of nitrogen in a vegetative wheat plant. Physiol. Plant. 56:11-17.

Stoev, K. D., P.T. Marmarov, and I.B. Benchev. 1959. Chromatographic analysis of sugars and free amino acids in the sap of grapevines. Sov. Plant Physiol. 6:424-430.

van Bel, A.J.E. 1990. Xylem-phloem exchange via the rays: The undervalued route of transport. J. Expt. Bet. 227:631-644.

van Die, J. 1959. Diurnal rhythm in the amino acid content of xylem exudate from tomato plants bleeding under constant environmental conditions. K. Ned. Akad. Wet. Proc. Ser. C. 62:50-58.

Wallace, A., S. Soufi, and H. Hemaidan. 1966. Day-night differences in the accumulation and translocation of ions by tobacco plants. Plant Physiol. 41:102-104. 